\title{
Semi-automated Flow Injection Method for the Determination of Iron (II) By 1,10-Phenanethroline
}

\section{AHMED SALEH FARHOOD ${ }^{1}$, AMAL SAADOON MAJEED ${ }^{2}$, LUMA AHMED MOHAMMED ALI¹ and DAKHIL NASSIRTAHA ${ }^{1}$}

\begin{abstract}
'Department of Chemistry, College of Science, University of Babylon, Babylon, Iraq. ${ }^{2}$ Sub-Department of Basic Science, College of Nursing, University of Kufa, Kufa, Iraq. *Corresponding author E-mail: alnakashluma@ Yahoo.com
\end{abstract}

http://dx.doi.org/10.13005/ojc/330653

(Received: May 18, 2017; Accepted: June 07, 2017)

\section{ABSTRACT}

The research is included determination of $\mathrm{Fe}$ (II) via its reaction with 1,10-phenanethroline to form light-red complex which is absorbed at $\lambda_{\max }=510 \mathrm{~nm}$. Home-made flow injection valve is designed with two loading loops, L1 and L2. A series of studies are conducted represented by fixing physical and chemical optimum conditions, dead volume, repeatability, dispersion coefficient, construction calibration graph, and application of the method. The dead volume is zero for the system which it has high repeatability $(n=8)$ with RSD and SD 0.6 and 0.05 respectively. The dispersion coefficient is 1.68 at the concentration $10 \mathrm{ppm}$. The range of measurements of calibration graph is $(0.05-18.00) \mathrm{ppm}$ with limit of detection $(\mathrm{S} / \mathrm{N}=3) 0.05 \mathrm{ppm}$.

Keywords: Home-made Flow Injection Valve, Determination of Fe(II), 1,10- Phenanthroline reagent

\section{INTRODUCTION}

Flow injection analysis (FIA) method is used in various analytical fields, which has a prominent role in agricultural, industrial, pharmaceutical and environmental fields. Flow injection technique is discovered and patented by the researchers Ruzicka, Hansen, and Stewart in 19751. One of the main flow injection technique features are the ability of analysing the very small volumes of samples and reagents, high sampling rate, low detection limits, wide extent of concentrations, ability of miniaturization of the apparatuses, high repeatability of readings, less personal mistakes comparatively with the other techniques, and conversion the reactions of open system to the reactions of closed system ${ }^{2-6}$.

The FIA system consists of many parts such as, peristaltic pump, manifold, detector, and recording device of signal ${ }^{7}$. Flow injection valve is the most important part of the manifold and considered as the heart of FIA system, which is used for injecting the chemical reaction solutions ${ }^{8-11}$. The sample-reagent segment is formed after loading process of the reaction components toward the detector by carrier stream rapidly ${ }^{12}$. When the sample-reagent segment reaches to the flow cell inside the detector, the signal is recorded as a sharp peak. The signal with height, area, and width is recorded with time of sample analysis ${ }^{13}$. 
Iron is the most common element in Earth, which is never found in free elemental state, therefore, iron is extracted from its ores. Iron is considered as one of the essential trace elements in biological systems. The average amount of iron is over than $4 \mathrm{~g}$ in human body. Iron plays very important roles in biological systems including $\mathrm{O}_{2}$ transport in haemoglobin, regulation of gene expression, and regulating electron transfer, radical, and redox catalysis in enzymes ${ }^{14,15}$.

The phenanthroline (phen) or 2,2'-bipyridine (bipy) reagent is heterocyclic organic compound with the formula $\mathrm{C}_{12} \mathrm{H}_{8} \mathrm{O}_{2}$ and absorbs at a wavelength of $265 \mathrm{~nm}$. Phenanthroline reagent is in the form of white-colored crystalline and characterized by the formation of strong complexes with most metal ions so it is used as a common ligand in coordination chemistry. It is binds metals more tightly since it has two chelating nitrogen donors. $\left[\mathrm{Fe}(\text { phen })_{3}\right]^{2+}$ complex is called as "ferroin" and well-studied which is characterized with deep red-colored and stable in acidic medium ${ }^{16,17}$. 1,10-phenanthroline is used for the determination the trace amount of Fe (II) and has the chemical structure in Figure.1.<smiles>c1cnc2c(c1)ccc1cccnc12</smiles>

Fig.1. Chemical Structure of 1,10- Phenanthroline

The aim of this research is designing flow injection system for the determination of $\mathrm{Fe}$ (II) including home-made flow injection valve from available, inexpensive, and environmentally friendly materials. The proposed method has many features such as, rapidity, low cost, low consumption of reagents, and satisfactory results.

\section{EXPERIMENTAL}

\section{Designing Stages of Flow Injection Valve}

An integrated flow injection unit is designed for the determination of Fe (II) by using home-made valve with capacity loading of two solutions at certain stages, including firstly pumping the water as a carrier solution to the system, secondly injecting the sample of Fe (II), thirdly injecting the solution containing the reagent 1,10- phenanthroline, the buffer solution $(\mathrm{pH}=5)$, and hydroxyamine hydrochloride and fourthly loading the injected solutions to the detector with helping of the carrier stream. The Fig. (2),(3),(4), and (5) show the four stages mentioned above in details.

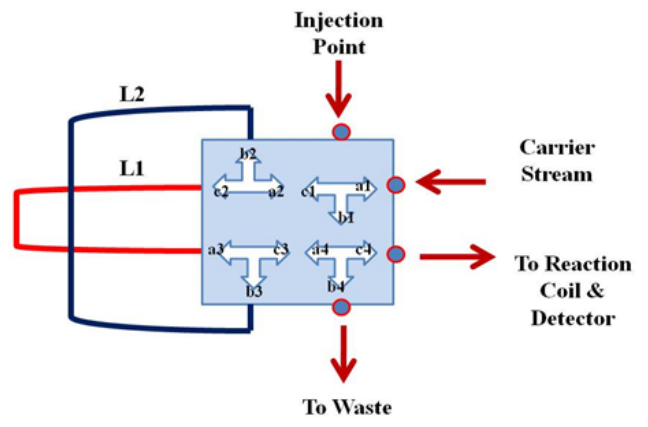

Fig.2. Passing distilled water as carrier stream to all parts of flow injection system, the directions a1, c1, a2, b2, c2, a3, b3, c3, a4, b4, and c4 are opened but the direction b1 is closed

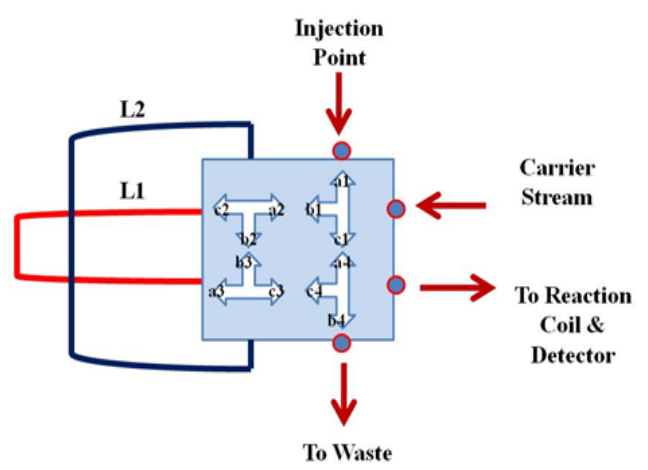

Fig.3. Injection of Fe (II) into the specified loop (L1), the directions a1, b1, a2, c2, a3, c3, b4, and c4 are opened but the directions $c 1, b 2, b 3$, and a4 are closed

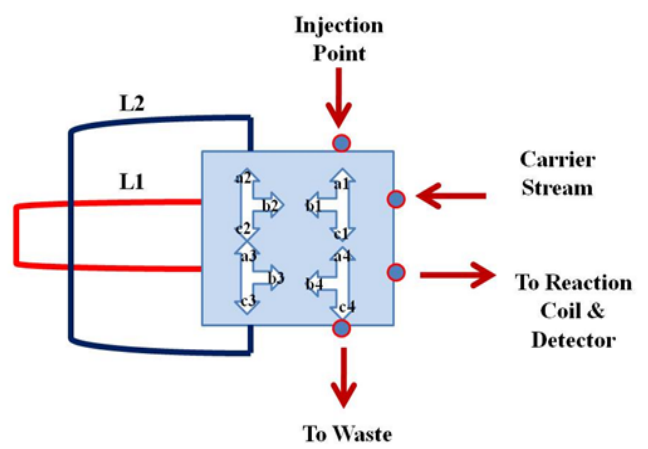

Fig.4. Injection of 1,10- phenanthroline in the specified loop (L2), the directions a1, b1, a2, b2, b3, c3, b4, and c4 are opened but the directions c1, c2, a3, and a4 are closed 


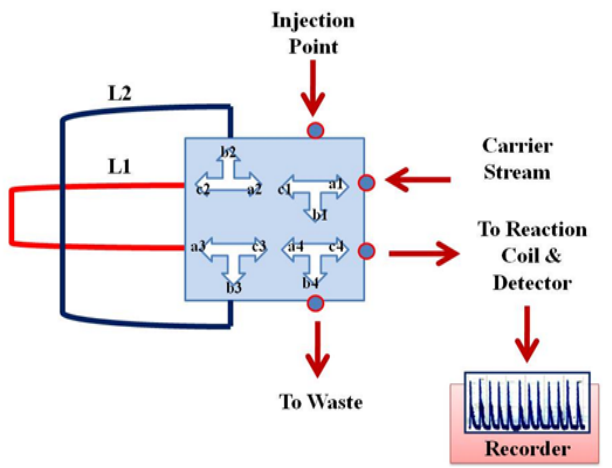

Fig.5. Loading sample-reagent segment toward the detector and recording the signal, the directions

a1, c1, a2, b2, c2, a3, b3, c3, a4, b4, and c4 are opened but the direction b1 is closed

The chemical reaction between Fe (II) and reagent requires the mixing of four solutions: the sample $\mathrm{Fe}$ (II), the reagent 1,10-phenanthroline, hydroxylamine hydrochloride solution, and buffer solution. The quaternary home-made valve makes the loading of four solutions easier and more quickly via injecting these solutions into two loops only. L1 and L2 represent to the two loops of the valve which their volumes and capacities are calculated by using the relation $V=\pi r^{2} L$, as shown in table (1).

Table.1: Calculation the volumes of injection valve loops

\begin{tabular}{lcc}
\hline $\begin{array}{l}\text { Seq. } \\
\text { No. }\end{array}$ & $\begin{array}{c}\text { Length of Loop } L(\mathrm{~cm}) \\
\text { with radius } r=0.5 \mathrm{~mm}\end{array}$ & $\begin{array}{c}\text { Volume V } \\
(\mu \mathrm{L})\end{array}$ \\
\hline 1 & $\mathrm{~L} 1=10$ & 78.50 \\
2 & $\mathrm{~L} 2=30$ & 235.71 \\
\hline
\end{tabular}

\section{Instrumentation}

A peristaltic pump (ISM796, Switzerland), the homemade flow injection valve, UV-Visible spectrophotometer (Apple PD-303UV, Japan), flow cell (450 $\mu \mathrm{L}$, Helmma), kompensograph (C 1032 Siemens, Germany), and Teflon tubing throughout of internal diameter i.d. $=1 \mathrm{~mm}$ are used.

\section{Reagents and Solutions ${ }^{16,18-21}$}

All chemicals are of analytical-reagent grade and used without further purification. The following solutions are prepared by using distilled water.

1. Fe (II) solution: Fe (II) solution of $100 \mathrm{ppm}$ is prepared by dissolving $0.0665 \mathrm{~g}$ of ferrous ammonium sulphate $\left[\mathrm{Fe}\left(\mathrm{NH}_{4}\right)_{2}\left(\mathrm{SO}_{4}\right)_{2} \cdot 6 \mathrm{H}_{2} \mathrm{O}\right]$ in $100 \mathrm{~mL}$ of distilled water.
2. Hydroxylamine Hydrochloride solution: $5 \% \mathrm{w} /$ $v$ of $\mathrm{HAC}\left[\mathrm{NH}_{2} \mathrm{OH} . \mathrm{HCl}\right]$ is prepared by dissolved $5 \mathrm{~g}$ of $\mathrm{HAC}$ in $100 \mathrm{~mL}$ of distilled water.

3. 1,10-Phenanthroline solution: 1.10-phenanthroline monohydrate of $100 \mathrm{ppm}$ is prepared by dissolving $0.01 \mathrm{~g}$ in $100 \mathrm{~mL}$ of distilled water and adding 2 drops of concentrated hydrochloric acid then the solution is heated to $70^{\circ} \mathrm{C}$ without boiling to facilitate the process of dissolving.

4. Buffer solution: first, $0.1 \mathrm{M}$ of glacial acetic acid -with specific gravity 1.05 g.L - $^{-1}$ and percentage $90 \%$ - is prepared followed by dissolving $1.0 \mathrm{~g}$ of sodium acetate trihydrate in glacial acetic acid solution to get $0.1 \mathrm{M}$ of buffer solution.

\section{RESULTS AND DISCUSSION}

\section{Calibration of Pump Speed}

This study is conducted to calibrate the speed of the peristaltic pump and calculate the volume for the solutions per minute at different values of pump speed by using stopwatch. The results are illustrated in table (2) and Figure (6).

Table.2: Calculation Flow Rate

\begin{tabular}{cc}
\hline Speed of Pump (rpm) & Flow Rate $\left(\mathrm{mL} \cdot \mathrm{min}^{-1}\right)$ \\
\hline 40 & 2.3 \\
50 & 2.9 \\
60 & 3.1 \\
70 & 3.4 \\
80 & 3.9 \\
90 & 4.3 \\
\hline
\end{tabular}

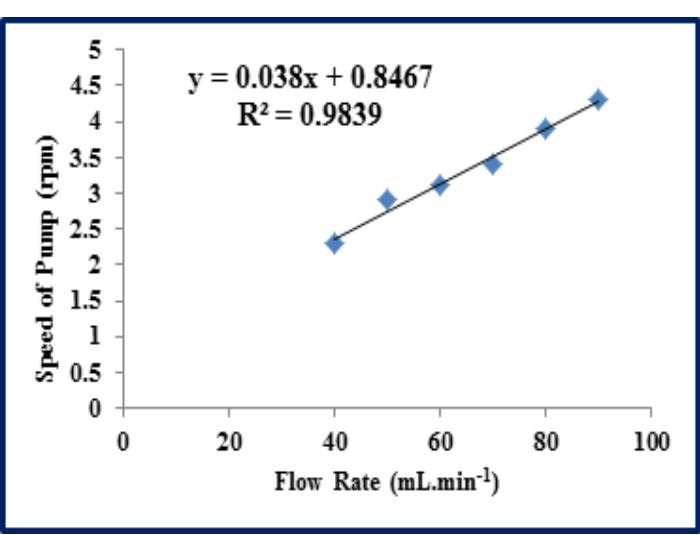

Fig.6. Relationship Between Speed of Pump (rpm) and Flow Rate (mL. $\left.\mathrm{min}^{-1}\right)$ 
Optimum position for Injecting sample \& reagent Choosing the optimum position effects on the value and the sensitivity of the response when the solutions are injected into the valve at different volumes and capacity of loops. The effect of position replacement for both $\mathrm{Fe}$ (II) and reagent is studied at $\lambda_{\max }=510 \mathrm{~nm}, 12 \mathrm{ppm}$ of $\mathrm{Fe}$ (II) and 1,10-phenanthroline reagent, flow rate of $3.1 \mathrm{~mL}$. $\mathrm{min}^{-1}$, and length of reaction coil is $35 \mathrm{~cm}$. Table (3) and Fig.(7) show that the injecting of 1,10-phenanthroline reagent and Fe (II) into L1 and L2 -with the capacities $78.50 \mu \mathrm{L}$ and $235.71 \mu \mathrm{L}$ respectively-results in response with $4.5 \mathrm{~cm}$ of height. The changing of injecting positions results in response with $6.9 \mathrm{~cm}$ of height and this is agreed with the literatures ${ }^{16,17}$.

Table.3: Optimum Positions for Reagent \& Sample in The Injection Valve

\begin{tabular}{lll}
\hline $\begin{array}{l}\text { Seq. } \\
\text { No. }\end{array}$ & Injecting Position & $\begin{array}{c}\text { Response } \\
\text { (cm) }\end{array}$ \\
\hline 1 & $\begin{array}{l}\text { Injecting of 1,10-phenanthroline } \\
\text { into L1 and Fe (II) into L2 }\end{array}$ & 4.5 \\
2 & $\begin{array}{l}\text { Injecting of 1,10-phenanthroline } \\
\text { into L2 and Fe (II) into L1 }\end{array}$ & 6.9 \\
\hline
\end{tabular}

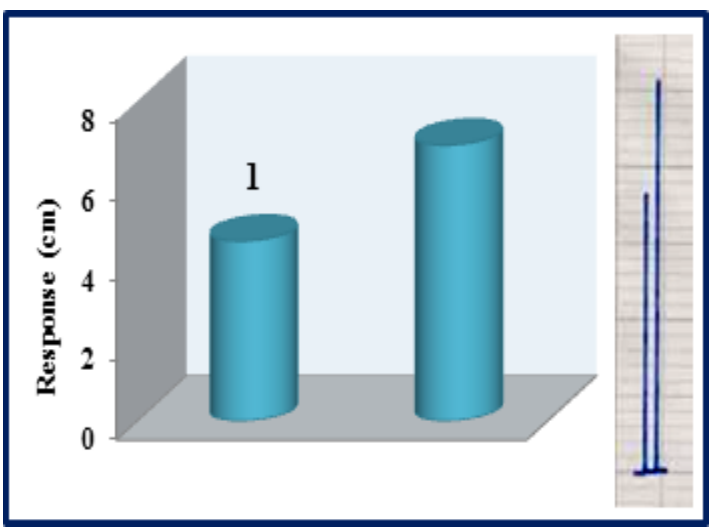

Fig.7. Effect of injecting position on the height of response

\section{Effect of Carrier Stream Flow Rate}

The dilution is lesser at slow flow rates because decreasing flow rate increases the sample retention time before moving to the detector and the interaction between the sample and the detector reaches the state of equilibrium and therefore the response will be higher at slow flow rate ${ }^{22}$. The slow flow rates show a wide, double, and distorted peak.
Studying the effect of changing flow is conducted at $\lambda_{\max }=510,12 \mathrm{ppm}$ of both sample and reagent, the injection positions are L1 and L2 for sample and reagent respectively, and the length of reaction coil is $35 \mathrm{~cm}$. The range of flow rate is $(1.9-4.3) \mathrm{mL}$. $\mathrm{min}^{-1}$ and the results are illustrated in table (4) and Figure (8).

Table.4: Effect of changing flow rate on the response

Flow Rate (mL.min. $\left.{ }^{-1}\right) \quad$ Response (cm)

\begin{tabular}{ll}
\hline 1.9 & 3.7 \\
2.3 & 5.1 \\
2.9 & 5.3 \\
3.1 & 5.8 \\
3.4 & 7.0 \\
3.9 & 5.3 \\
4.3 & 5.3 \\
\hline
\end{tabular}

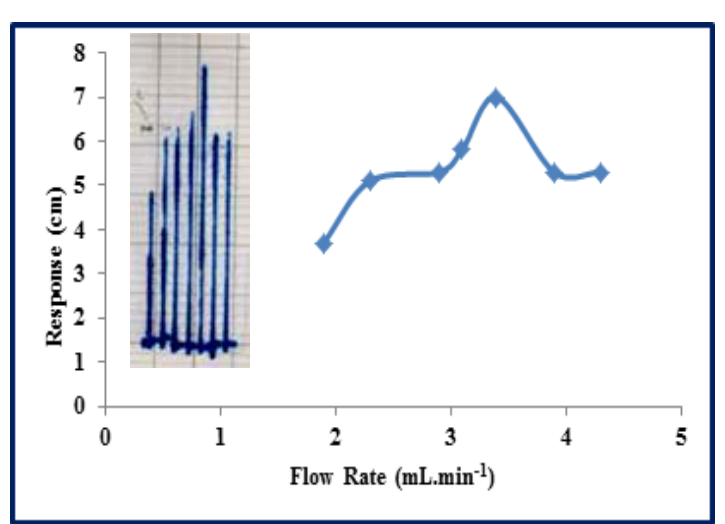

Fig.8. Effect of changing flow rates on the sensitivity of response

According to table (4) and Fig. (8), the increase in flow rate from 1.9 to $3.1 \mathrm{~mL}$. $\mathrm{min}^{-1}{ }^{-1}$, the response gradually increases from 3.7 to $5.8 \mathrm{~cm}$, because the slower flow rate that provides longer time causes a dilution of the sample by the carrier stream solution. But at the higher flow rates, the shortest time for dilution of the injected sample is occurred and the response increases to $3.4 \mathrm{~mL}$. $\mathrm{min}^{-1}$. When the time is optimal and the samplereagent segment dilution is reduced, the response is reached to the maximum height at $7 \mathrm{~cm}$. Then increase the flow rate from 3.9 to $4.3 \mathrm{~mL}$. $\mathrm{min}^{-1}$ causes the response to be constant at a height of $5.3 \mathrm{~cm}$. The very high flow rates cause the solutions not to be fully mixed and lack equilibrium state of the reaction, therefore the response is reduced ${ }^{23-25}$. 


\section{Reaction Coil Length}

The length of reaction coil effects on the reaction and the fully mixing of the solutions to reach to equilibrium state. Also, shape, diameter, and length of the reaction coil effect on the formation of sample-reagent segment at the optimal time, and the sampling rate.

The effect of reaction coil length is studied at $\lambda_{\text {max }}=510 \mathrm{~nm}$, the concentration of $12 \mathrm{ppm}$ of $\mathrm{Fe}$ (II) and 1,10-phenanthroline reagent, flow rate $=3.4$ $\mathrm{mL} \cdot \mathrm{min}^{-1}$, and the injection positions of $\mathrm{Fe}$ (II) and 1,10-phenanthroline reagent are via $\mathrm{L} 1$ and $\mathrm{L} 2$ respectively. The effect of reaction coil lengths is studied at the range $(35-175) \mathrm{cm}$. The results are shown in table (5) and Figure (9).

Table. 5: Effect of Reaction Coil Length

\begin{tabular}{ccc}
\hline $\begin{array}{l}\text { Seq. } \\
\text { No. }\end{array}$ & $\begin{array}{c}\text { Reaction Coil } \\
\text { Length }(\mathrm{cm})\end{array}$ & $\begin{array}{c}\text { Response } \\
(\mathrm{cm})\end{array}$ \\
\hline 1 & 35 & 7.0 \\
2 & 60 & 9.1 \\
3 & 90 & 8.3 \\
4 & 115 & 8.7 \\
5 & 175 & 6.9 \\
\hline
\end{tabular}

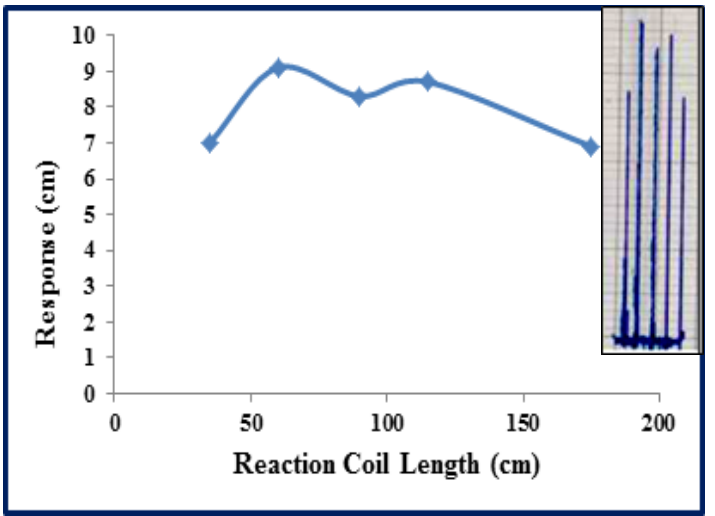

Fig.9. Relationship between Reaction Coil Length and Response

Relationship between Reaction Coil Length and Response

According to table (5), the increasing of reaction coil lengths from $35 \mathrm{~cm}$ to $60 \mathrm{~cm}$ leads to increase the height of response from $2.8 \mathrm{~cm}$ to 3.0 acutely. The reaction coil of length $35 \mathrm{~cm}$ does not allow good mixing for the reaction components but, the lengths $60 \mathrm{~cm}, 90 \mathrm{~cm}$, and $115 \mathrm{~cm}$ provide sufficient time for good mixing and reaching equilibrium state which causes maximum height of response at reaction coil length of $60 \mathrm{~cm}$. Fig. (9) shows reducing in the response height when the length of reaction coil is increase to $175 \mathrm{~cm}$ due to high dilution of sample-reagent segment. Especially, the reaction between Fe (II) and 1,10 -phenanthroline reagent is rapid and there is no need for further mixing to reach equilibrium state ${ }^{26}$.

\section{Repeatability}

Repeatability is repeating process of injection-at least six injections-at the same conditions to prove the precision of injection for the system $^{27,28}$. The repeatability is studied for eight injections $(n=8)$ at the same optimum conditions including: $\lambda_{\max }=510 \mathrm{~nm}$, the concentration of $12 \mathrm{ppm}$ of $\mathrm{Fe}$ (II) and 1,10-phenanthroline reagent, flow rate $=3.4 \mathrm{~mL}$. $\mathrm{min}^{-1}$, reaction coil length $=60 \mathrm{~cm}$, and the injection positions of $\mathrm{Fe}$ (II) and 1,10-phenanthroline reagent are via $L 1$ and $L 2$ respectively. Standard deviation S.D and relative s Standard deviation values are 0.05 and 0.6 respectively. The results are illustrated in table (6) and Figure (10).

Table.6: Repeatability for Eight Injections

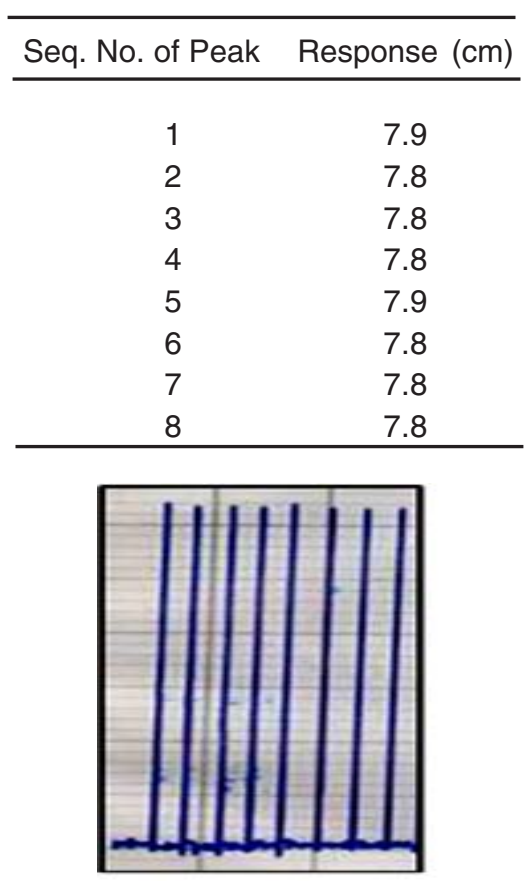

Fig.10. High Repeatability for Eight Injections 


\section{Dispersion Coefficient (D)}

Dispersion coefficient is studied through the comparison the form and height of response before dilution $\left(\mathrm{H}^{0}\right)$ and after dilution $\left(\mathrm{H}^{\max }\right)$ after fixing the optimum conditions, as illustrated in table (7) and Fig. (11). It has to be noted that the response height is reduced with dilution. The dispersion coefficient (D) is calculated as follows ${ }^{29}$ :

$\mathrm{D}=\mathrm{H}^{0} / \mathrm{H}^{\max }$

$D=13.1 / 7.8=1.68$

The dispersion coefficient value 1.68 means that the dilution is limited and considered in favor of the system.

\section{Table.7: Response with dilution and without dilution}

Response without Response with Dispersion dilution $\left(\mathrm{H}^{0}\right) \quad$ dilution $\left(\mathrm{H}^{\mathrm{max}}\right)$ coefficient $(\mathrm{D})$

\begin{tabular}{lll}
\hline $13.1 \mathrm{~cm}$ & $7.8 \mathrm{~cm}$ & 1.68 \\
\hline
\end{tabular}

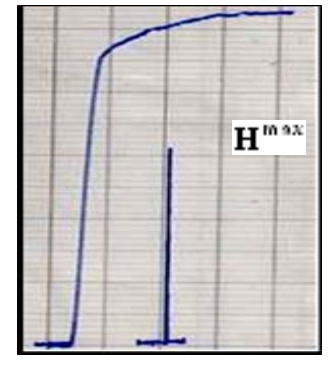

Fig.11. Dispersion Coefficient

\section{Dead Volume}

Dead volume is the remaining volume of any component of chemical reaction during loading process of solutions into injection valve. Dead volume is considered as a measure of FIA system efficiency. If the value of dead volume is not zero, that causes appearance of signal in the baseline. In this case, the injection valve is imperfect but the zero value of dead volume proves the high efficiency of FIA system. It has to be noted that all responses have the same baseline because the dead volume is zero $^{30,31}$.

\section{Sampling Rate}

Sampling rate is the number of analysed samples per one hour. The time of sample analysis is calculated from injection stage of reaction components and response appearance ascending to the maximum peak followed by the descending of response to the baseline. It is found that the time of analysis for one sample is 55 seconds; hence, the sampling rate is about 66 sample per hour, The sampling rate of about 66 sample per hour is considered good result according to the literature ${ }^{32}$.

\section{Calibration Graph}

This study is conducted at $\lambda_{\max }=510 \mathrm{~nm}$ after fixing the optimum conditions including: $12 \mathrm{ppm}$ of 1,10-phenanthroline reagent, flow rate $=3.4 \mathrm{~mL} \cdot \mathrm{min}^{-1}$, reaction coil length $=60 \mathrm{~cm}$, and the injection positions of $\mathrm{Fe} \mathrm{(II)} \mathrm{and}$ 1,10-phenanthroline reagent are via $L 1$ and $L 2$ respectively. The range of $\mathrm{Fe}$ (II) concentrations is (1.0-18.0) ppm with limit of detection (LOD=3.3S/N) $0.05 \mathrm{ppm}$ and the results are illustrated in table (8) and Fig. (12) in details.

Table.8: Calibration graph of Fe (II)

\begin{tabular}{lcc}
\hline Seq. No. & $\begin{array}{c}\text { Fe (II) concentration } \\
(\mathrm{ppm})\end{array}$ & $\begin{array}{c}\text { Response } \\
\mathrm{Y}(\mathrm{cm}) \mathrm{n}=3\end{array}$ \\
\hline 1 & 0.1 & 1.2 \\
2 & 0.5 & 1.8 \\
3 & 1.0 & 2.3 \\
4 & 2.0 & 2.9 \\
5 & 3.0 & 4.2 \\
6 & 6.0 & 5.2 \\
7 & 9.0 & 6.7 \\
8 & 11.0 & 8.3 \\
9 & 15.0 & 9.9 \\
10 & 18.0 & 13.4 \\
\hline
\end{tabular}

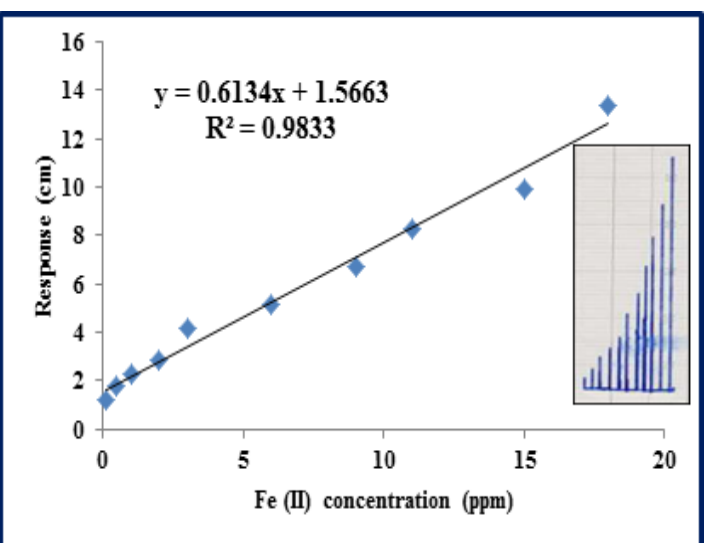

Fig.12. Calibration graph of Fe (II) 


\section{Statistical Analysis ${ }^{26,27}$}

The analysis of variance (ANOVA) and student "t" test, is conducted by using Table Curve $2 d$ v5.01 Systat Software. All measurements are replicated three times $(n=3)$ and the results are detailed in the tables (9) and (10).

According to the results in table (9), there is a linear relationship between the response and the concentration of $\mathrm{Fe}(\mathrm{II})$. Because $\mathrm{t}_{\text {cal }}$ is greater than $t_{\text {tab }}$ in both two methods, in $\mu$ FIA method $\left(t_{\text {cal }} 167.94>>t_{\text {tab }} 2.31\right)$ and $r=0.9853$.

The critical values $\mathrm{F}_{\text {tab }}\left(F_{9}^{1}=5.12\right)$ is less than the calculated values of $F\left(F_{\text {stat }}=469.861\right)$ in flow injection method. The results approach to linear state, because, there is significant difference at $95 \%$ confidence interval between the variance due to regression and the variance due to error (Table:10).

\section{Application}

The proposed method is successfully applied for prepared solution of $\mathrm{Fe}$ (II). The obtained results show good recovery as shown in table (11). The percentage of relative error and recovery are calculated by using the equations (2) and (3) respectively.

$$
\text { R. E. } \%=\frac{\text { Actualvalue-Measuredvalue }}{\text { Knownvalue }} \times 100
$$

Recovery $\%=100+$ R.E. $\%$

Table.9: Summary of linear regression equation results of the form $Y=b X+a$ for the determination of $\mathrm{Fe}(\mathrm{II})$

\begin{tabular}{|c|c|c|c|c|c|}
\hline $\begin{array}{l}\text { Linear } \\
\text { range } \\
\text { ppm }\end{array}$ & $\begin{array}{c}\text { No. of } \\
\text { measurements } \\
\text { (n) }\end{array}$ & $\begin{array}{c}\text { Straight line } \\
\text { equation } \hat{Y}=\left(a \pm \mathrm{s}_{\mathrm{a}} \mathrm{t}\right)+ \\
\left(\mathrm{b} \pm \mathrm{s}_{\mathrm{b}}\right)[\mathrm{Fe}(\mathrm{II})]\end{array}$ & $\begin{array}{l}\text { Correlation } \\
\text { coefficient } \\
\text { (r) }\end{array}$ & $\begin{array}{l}\text { Calculated } \\
\text { t-value }= \\
\frac{/ r \sqrt{n-2}}{\sqrt{1-r^{2}}}\end{array}$ & $\begin{array}{c}\text { Tabulated t-value } \\
\text { interval at } 95 \% \\
\text { confidence in } \\
\text { interval }\end{array}$ \\
\hline $\begin{array}{l}0.10- \\
18.00\end{array}$ & 10 & $\begin{aligned} \hat{Y} & =1.57 \pm 6.18+0.61 \\
& \pm 21.67[\mathrm{Fe}(\mathrm{II})]\end{aligned}$ & 0.9916 & 167.94 & 2.31 \\
\hline
\end{tabular}

$\hat{Y}=$ Estimated response $(\mathrm{cm})$

Table.10: The results of ANOVA test for straight line equation $Y=b X+a$

\begin{tabular}{|c|c|c|c|c|c|}
\hline $\begin{array}{l}\text { Source of } \\
\text { variance }\end{array}$ & $\begin{array}{c}\text { Sum of squares } \\
\text { (SSq) }\end{array}$ & $\begin{array}{l}\text { Degree of freedom } \\
\text { (Df) }\end{array}$ & $\begin{array}{l}\text { Mean squares } \\
\text { (MSq) }\end{array}$ & F-statistic $F=\frac{s_{1}^{2}}{s_{0}^{2}}$ & F-tabulated \\
\hline $\begin{array}{l}\text { Due to } \\
\text { regression }\end{array}$ & $\begin{aligned} & \sum\left(\hat{Y}_{i}-\bar{Y}\right)^{2} \\
= & 139.55293\end{aligned}$ & $v_{1}=1$ & $S^{2}{ }_{1}=139.55293$ & 469.861 & 5.12 \\
\hline $\begin{array}{l}\text { Due to error } \\
\text { (about } \\
\text { regression) }\end{array}$ & $\begin{array}{c}\sum_{\left(\mathrm{Y}_{\mathrm{i}}-\hat{Y}\right)^{2}} \\
=2.376072\end{array}$ & $v_{2}(n-2)=8$ & $\mathrm{~S}_{0}^{2}=0.297009$ & & \\
\hline Total & 141.929 & $v_{\text {Total }}(n-1)=9$ & & & \\
\hline
\end{tabular}

Table. 11: Determination of Fe (II) in stock solution by using the home-made flow valve

\begin{tabular}{lcccc}
\hline Sample & Taken concentration ppm & Found concentration ppm & $\mathrm{E}_{\mathrm{r}} \%$ & Recovery\% \\
\hline $\mathrm{Fe}$ (II) & 10 & 10.03 & +0.3 & 100.3 \\
\hline
\end{tabular}




\section{CONCLUSION}

The design of flow injection system for the determination of $\mathrm{Fe}$ (II) needs no expensive equipment compared to other techniques and modern flow injection systems are expensive. The determination of $\mathrm{Fe}$ (II) by the hand-designed and local unit is characterized by rapid analysis and wide range of concentrations, non-consumption of chemicals in large quantities, use of very low volumes and low concentrations of reaction solutions. In addition to the dead volume of the valve is zero indication to high efficiency of flow injection system as well as the high repeatability of the system.

\section{ACKNOWLEDGEMENT}

We are grateful for the cooperation of the Chemistry Department at the Faculty of Science, University of Babylon, with our team ( Flow Injective Analysis Team, headed by Prof. Dr. Dakhil Nassir Taha ) in the same faculty for providing support and facilities for the team to get the best results.

\section{REFERENCES}

1. Trojanowiez, M. "Advances in Flow Analysis", Wiley-VCH Verlag GmbH and Co. KGaA , 2010.

2. Troanowicz, M. "Flow Injection Analysis, Instrumentations and applications", $1^{\text {st }}$. Edition, World Scientific Publishing USA, 2000.

3. Naser. N.A.; Kadim. K.H.; Taha. D.N., Synthesis and characterization of an organic reagent 4-(6-Bromo-2-Benzothiazolylazo) Pyrogallol and its analytical application, J. Oleo Sci. 2012, 61(7), 387-392.

4. Farhood, A. S.; Mohammed, L. A. Ali ;Ali. F. F., Determination of Aniline Blue dye by Flow Injection Analysis With Home Made Valve, Orient. J. Chem., 2017, 33(2), 944-950.

5. Parikh. A.; Patel. K.; Patel. C.; Patel, B., J. Chem. Pharm. Res., 2010, 2(2),118-125.

6. Ruzicka, J. ; Hansen, E. H. , “Flow Injection Analysis", 2 ${ }^{\text {nd }}$ Edition, Wiley, New York, 1988.

7. Leamsomrong, K. ; Suttajit, M. ; Chantiratikul, P., Asian Journal of Applied Sciences, 2009, 2(2), 184 -190.

8. $\quad$ Lingyun, YU. ; Mengru, WU. ; Wei, D. ; Jing, J. ; Xinshen, Z. , Soil and Water Res., 2011, 6 (4), 198-204.

9. Taha, D.N.; Samaka, I.S.; Mohammad, L.A., Adsorption removal of dye from industrial effluents using natural Iraqi palygorskite clay as low cost adsorbent, J. of Asian Scientific Research, 2013, 3(9),945-955.

10. Taha, D.N.; Samaka, I. S.; Mohammad, L. A.; Naige, A. S., Adsorption Studies of Direct Red 28 Dye onto Activated Carbon prepared from low-cost material, Civil and Environmental
Research, 2014, 6(7)149-159.

11. Taha, D.N.; Samaka, I. S., natural Iraqi palygorskite clay as low cost adsorbent for the treatment of dye containing industrial wastewater, J. Oleo Sci. 2012, 61(12).

12. Shriver, D.; Weller, M.; Overton, T.; Rourke, J. ; Armstrong, F., "Inorganic Chemistry", $6^{\text {th }}$ Edition, W. H. Freeman and Company, 2014.

13. Strohfldt, K. A., "Essentials of Inorganic Chemistry: for students of pharmacy, pharmaceutical sciences, and medicinal chemistry", $1^{\text {st }}$ Edition, John Wiley and Sons Ltd, 2015.

14. Lee, G.F.; Stumm, W.; J. American water works Association,1960,52(12),1567-1574.

15. Belcher, R., Application of chelate Compounds in Analytical Chemistry, Pure and Applied Chemistry, 1973, 34, 13-27.

16. Wells, M. L.; Price, N.M.; Bruland, K.W., Elsevier Marine Chemistry, 1995, 48,157-182.

17. Niazi, A., J. Croatica Chemica Acta, 2006, 79 (4), 573-579.

18. Irhan, N. D.; Elmali, F.T., Turk J. Chem., 2003, 27, $315-321$.

19. Faizulahd, A.; Townshend, A., Analytical Chimica Acta, 1986, 167, 225-231.

20. Osborne, O.; Pring, A.; Lenehana, C., Talanta, 2010, 82, 1809-1813.

21. Han, S., Microchim Acta, 2010, 168,169-175.

22. Payan, M.; Lopez, M.; Torres, R.; Navarro, M.; Moch, M., Talanta, 2009, 79,911-915.

23. Taha, D. N.; Obaid, Z. S., J. of Research of Pharmaceutical, Biological and Chemical Science, 2016, 7(6). 
24. Abbas, G.J.; Mashkour, M.S.; Taha, D.N., J. of Purity, Utility, Reaction, and Environment, 2016, 5(4), 92-105.

25. Akyar, I. , (Ed.), “Wide Spectra of Quality Control", In Tech, 2011.

26. Watson, D.G., "Pharmaceutical Analysis-A Textbook for Pharmacy Students and Pharmaceutical Chemists", Churchill Livingstone, 1999.

27. Taha, D.N.; Majeed, A.S. “Innovative Design of Flow Injection Tri-valve and Its Use for the Determination of Trace Amounts of Bi (III)", Iraqi patent, 4390, C.O.S.Q.C., 2015.

28. Taha, D.N.; Majeed, A.S., " Innovation of Hexagonal Flow Injection Valve with Two Different Levels Locally and Its Use for Bi (III) Determination Using Merging Zone Technique", Iraqi patent, 4605, C.O.S.Q.C., 2016.
29. Taha, D.N; Majeed, A.S., "Innovation of Flow Injection Hexagonal-double Valve with Two Different Levels and Its Use for the Determination of Bismuth (III) in Some Pharmaceutical formulations", Iraqi patent, 4566, C.O.S.Q.C., 2016.

30. Majeed, A.S.; Taha, D.N. "New Innovative Designs of Flow Injection and Microfluidic Systems for the Determination of Bismuth (III) in Pharmaceutical and Environmental Samples", Ph.D. Thesis, Babylon University, 2015.

31. Miller, J.N.; Miller, J.C.,"Statistics and Chemometrics for Analytical Chemistry", $6^{\text {th }}$ Edition, Pearson Education Limited, 2010.

32. Hibbert, D.B.; Gooding, J.J., "Data Analysis for Chemistry: An Introductory Guide for Students and Laboratory Scientists", Oxford University Press, Inc., 2006. 